\title{
Sensory Branding: A New Era in Dentistry
}

\author{
Antoniadou Maria ${ }^{1 *}$ and Devetziadou Marina ${ }^{2}$ \\ ${ }^{1}$ Assistant Professor, Dental School, National and Kapodistrian University of Athens, Greece \\ ${ }^{2}$ Dentist, Dental School, National and Kapodistrian University of Athens, Greece
} *Corresponding author: Antoniadou Maria, Assistant Professor, Dental School, National
and Kapodistrian University of Athens, Greece.
Received Date: September 29, 2020

Published Date: October 08, 2020

\begin{abstract}
Aim: To build brand awareness and brand identity in today's recessed market, dental professionals need to find new ways to stimulate potential patients. Senses have been incorporated in branding techniques in all business fields including health sectors. The aim of this article is to improve the availability of marketing techniques in order to brand dental services through the five senses.

Methods: In this article a non-systematic review has taken place for the theme of sensory dental branding including relevant marketing techniques for the last decade.

Results: The implementation of every sense in dental marketing and branding is expected to have a great amount of benefits for both the dentist and his patients. Sensory branding can influence patient's feelings and behavior by using his/her senses in order to raise awareness, create positive perceptions and differentiate the dental professional from competitors.
\end{abstract}

Conclusion: Multisensory marketing experience seems to lead to stronger dental brand recognition and image in a long term.

Keywords: Sensory branding; Five senses; Dental marketing; Dental branding; Quality management; Stimuli

\section{Introduction}

In health care sector, branding is the process of shaping a unique name and impression in the mind of the patients [1]. It is the aura of the enterprise or the dental office. In the world of business industry, branding is as old as the therapeutic approach itself. In the private practice health care system, it is not very common yet or it is performed without realizing it is branding that takes place. Dentistry borrowed the term of branding from the management field. The importance of branding grew stronger during the nineteenth century along with the development of industrialization [1]. After the industrial revolution, branding was transformed from a simple entity with limited application, whose creation, interpretation, and control are mostly enacted by one person (i.e. its creator), to a complex entity that is multi-dimensional and multi-functional. This entity receives influences from a variety of actors (e.g. the brand manager, the consumer/patient, the media, the marketing researcher, technology etc.) [1,2].

Nowadays, the evolution of branding is largely a phenomenon that could have only occurred starting at the end of the nineteenth century and into the twentieth century, mainly due to the growth of nationwide magazines and media (TV, radio, print advertising, e-marketing, etc.) [2-4]. In today's competitive business environment, the market is swamped with new brands. The intensity of brand war is increasing day by day and so differentiation through promotion, creativity and innovation is vital. Recently, one of the most vital branding elements is the sensory branding which aims to seduce the customer by influencing his senses [5]. Senses support a vital section of human life [6,7]. People understand nearly everything in the world, through their senses [6]. 
Thus, sensory branding is an emerging business discipline that applies analytical techniques to combine the use of sensory stimuli, such as sight, sound, smell, touch and taste in order to develop stronger brands than conventional audio-visual branding techniques alone [8]. The concept of sensory branding plays a vital role in enhancing the sale-ability of a product or service. But for a product, its functionality makes it easier to promote as compared to a service. In the service sector like dentistry, the intangibility factor needs to be well defined to attract and convince the patient in order to collaborate [9].

Sensory branding also allows professionals and companies to use new communication channels [10] and understand better the world around them [6]. The senses are the link to memory and can tap right into emotion [11]. It seems though that using two-dimensional perspective of branding, which includes only audiovisual stimulus is not enough to differentiate a brand in the patient's mind. Humans get more aware of brands when all five senses are incorporated and used in daily base. It is stated that "the brand building of the future will move from a two-sensory approach to a multisensory approach" and that "a total sensory experience would at least double, if not triple, the consumer's ability to memorize the brand" [8].

Since most companies are recently focusing on all human senses for exceptional branding trends, this article focuses on applying a multidimensional desire also in the field of dental branding. Under this scope, branding ideas based on every sense are discussed and new sensory approaches are proposed for a successful modern dental office.

\section{Sensory Branding}

The aim of sensory branding is to use all five senses at the same time to create a five-dimensional experience for the consumer/ patient [8]. Each of the five senses provide an experience whereas all of them together create a whole perspective of a sensory experience [12]. Nowadays companies are focusing on sensory stimuli to build powerful brands and are delivering their branding message by touching on as many human senses as possible. They moved from a classic brand building (two-dimensions) to a sensory brand building, also called 5D branding [5]. Emotional branding or sensory branding is the marketing strategy that is investigating the emotional relationships between consumer/patient and the brand [6]. It reaches out to customers/patients in a more personal and intimate way by putting the human brain, with its five senses, at the center of marketing [13].

So, the brain of an individual registers a brand, and an image is created in terms of mental conceptions and mental images. This image is a result of the experiences an individual has with a firm/ professional or a brand [9]. The more he involves with the sense, the more he will be able to remember the brand [8]. Generally, by appealing to five senses, dental brands should aim creating strong memories in patients' mind. This concept leads to stronger bonds between patients and brands, so that the consumer/patient will turn to the brand repeatedly [9]. Research shows that the supreme sensory experience which is both subjective and personal in nature leads to not only customer satisfaction but also "customer delight". So, to surprise customers is important because it gets a marketer beyond satisfaction [9]. Satisfaction implies the meeting and fulfilling of expectations, but surprise creates even something more. It creates delight. Patient's delight is essential in order to build brand loyalty and patient franchising. This fact increases the chances of advocacy and repeated visits. On the other hand, dental patients do not have enough time to get attracted to their dentist via advertisements, and therefore sensory branding could enrich the experience and emphasize the cooperation.

\section{Aspects of Sensory Branding and their Effectiveness}

With the different themes of sensory marketing that exist, it is interesting to gain insight into the roles that each sense plays in the specific field of dentistry. The specific aspects of what makes sensory branding so effective remain relatively unclear. Some sensory marketers believe that one sense dominates over the other four. Vision for example is the most important and persuasive sense with smell being the second most important one, followed by hearing, taste and touch [14]. It is reported elsewhere that sound can help people generate moods by creating feelings and emotions [9]. Taste and smell are also closely connected, although smell is 10,000 times more sensitive as it taps right into the memory [15]. Uddin [8] has mentioned that it is important to concentrate on sight and sound in order to share the identity of a brand. Nevertheless, it is also required to combine the other senses in order to create an emotional atmosphere by giving a memorable experience of the brand to the patient [7]. In general, input to the mind and brain is originated from all five senses. In fact, senses play key and complicated role for discrimination to select a brand [6].

\section{Sight}

Vision is the most powerful among the other senses. The cooperation between brain and eyes are perceived to be better than any machine ever invented as it takes 45 milliseconds for humans to detect a visual object [8]. For obvious reasons, sight is a sense that dominates over the other four and it is the most seductive sense of all [11]. Maybe this is the reason why the sight is the most utilized sensory stimulus in marketing. Sight is generally perceived to be the most powerful of the human senses, as eyes enables us to communicate with others by different methods, for example a quick double person communication when looking each other [6]. Other scientific studies additionally show that most information comes to people through a form of visualization. Sight is the sense everybody uses most frequently every second that we're awake. Therefore, it is the most relied upon and important sense for most humans and often drives the first impression [11]. 
Sight plays a significant role in the perception of a brand as the stimulation of sight can enhance the brand image and the perceived quality [8]. By applying a visual sensory strategy, a brand's identity is also expressed visually and becomes a distinguishing feature [12]. A characteristic example that confirms sight as the most powerful tool is that before Coca-Cola began promoting Santa Claus in its signature color, red, he traditionally wore green. Sight is such an important marketing tool that companies are nowadays modifying the appearance of their brands to accommodate the preferences of a growing generation of people [16]. The role of the image of the brand (for both experienced and inexperienced consumers) is very important, because by purchasing something that they believe is in greater consistency with their image of the brand, consumers try to strengthen the image of the brand in their mind, and this enables them to make a relation between themselves and the product or service [16]. The result is that patients, as in our case, prefer brands that can be reflected onto a homologous self-representation of themselves. In other words, people seek out brands/professionals that have qualities that resonate with certain aspects of themselves or their values.

Table 1: Five types of processing visual stimuli.

\begin{tabular}{|c|c|}
\hline Pre-conscious & $\begin{array}{c}\text { Patients are unconscious of the presence of stimuli, so a subliminal persuasion occurs, and the judgment is assimilated in a positive } \\
\text { way toward the visual stimuli. }\end{array}$ \\
\hline Non-conscious & $\begin{array}{l}\text { Patients are conscious of the presence of stimuli but unaware of its influence on their mindset and its effect on their decision-making } \\
\text { process. }\end{array}$ \\
\hline Heuristic & $\begin{array}{c}\text { Patients make their decision based on easily accessible cues due to their low level of motivation or cognitive resources to examine the } \\
\text { visual information in detail. }\end{array}$ \\
\hline Systematic & $\begin{array}{l}\text { Patients do have a high level of motivation, opportunity and ability to make their judgment and choose their ideal dental service } \\
\text { based on the visual information provided. }\end{array}$ \\
\hline Hardwired & $\begin{array}{l}\text { Patients are aware of the stimuli and they can control its influence on their own judgement. The key difference between the hard- } \\
\text { wired model and the four others is that the first one is controllable. }\end{array}$ \\
\hline
\end{tabular}

Other ways to take advantage of sight is by shape and by the interior design of dental office. Statistics show that 40 percent of all perfume purchase decisions are based on the design of the bottle [16]. On the other hand, an unattractive design might depress mood and lead people to focus more on analyzing details, expecting and detecting problems [5]. The Coca-Cola bottle for example is designed in a manner that even if the bottle broke down a person can still easily recognize what brand the bottle belongs to [10]. It is widely recognized that colors have also a strong impact on people's emotions and feelings (Naya et al. 2004), but colors also profoundly impact their productivity, for better and for worse. Colors are rich with symbolism. This symbolism can be apparent in how an individual associate's colors with things, objects, physical space or even ideas. While consumers are exposed to brands through various marketing efforts and brand experience, it is possible that they use colors for meanings of brand search and identification too.

Color preferences seems to evoke emotionally laden responses, such as feelings of attraction to a product, brand or service. That is why by modifying the colors on the walls of the dental office reception or practice could alter the impact on the sentiment of
According to Krishna, et al. [17] there are five types of processing visual stimuli, which have been adapted to healthcare industry's data in (Table 1). The complexity of the visual process shows that appeal to sight is risky since reactions and judgments of consumers are not precisely predictable [8]. To avoid making mistakes, companies should use sight in the right way according to their image and goals. Visual stimuli such as colour, design, graphics, lighting and interior design certainly impact the visual perception of a brand [11]. People also judge a brand's name according to visual attractiveness of letters, words and symbols (in other words its writing style) or according to how it sounds. It is important that names, logos and other visual elements, for example, in advertising and campaign promotions, constitute a coherent whole [11]. A catchy logo, a colourful poster or a stylish cover can encourage the sense of sight to dominate over all other senses in patients' decisionmaking process. Also, many companies have largely succeeded in that people are able to recognize small fragments of logos and apply it to the overall picture of the logo [16]. In this way, their logos are more visible and easier for consumers to quickly recognize. patients. It seems that colours are fundamental in the perception of a brand and can highlight the most important attributes and associations of it. Prominent colour preferences probably attract stronger feelings [12] and therefore it is vital to select colours carefully. If colours are chosen correctly, they can be used strategically to reinforce and communicate the desired image of the dental office. The color of the brand could also be inflicted on the uniform of the staff for an organized branding effort [10].

For instance, the color red has been associated with excitement, orange has been perceived as distressing and upsetting, purple as dignified and stately, yellow as cheerful, blue has been associated with comfort and security and green has been found to have a retiring and relaxing effect. Also, it was reported that white was seen to be positive and was associated with the feelings of innocence, peace, and hope, but reasons given for negative emotional responses to white consistently showed that white elicited the feelings of emptiness, loneliness, and boredom [18]. Finally, the color gray was mainly associated with negative emotions (89.8\%), including the feelings of sadness, depression, boredom, and confusion, as well as tiredness, loneliness, anger, and fear [19]. 
Colors can also be described in temperature terms, such as "warm" or "cool" as related to the dominant wavelength of the color [20]. Innate color effects could also explain why the cold and shortwavelength colors like blue and green are generally preferred to the warm and long-wavelength colours red and yellow [19]. The cool colors (e.g., blue, green, purple) are generally considered to be restful and quiet, while the warm colors (e.g., red, yellow, orange) are active and stimulating [20]. Cool colors such as blue and green make a space restful and increase spaciousness; however warm colors such as red, orange, and yellow make a space less spacious, while increasing stimulation [18]. Furthermore, people exposed to red and yellow colors usually report higher levels of anxiety than people exposed to cool blue and green colors [21]. As a result, colors blue and green are considered ideal for a dental office as they reveal the feelings of relaxation, refreshment and calmness, followed by happiness, comfort, peace, and hope.

\section{Smell}

Smell is the sense with the greatest emotional and sensitive impact. It transfers directly to the limbic system, the part of the brain where the emotions and memory are handled [6]. Unlike vision, scent processing is slow. It takes 10 times as long to detect an odour than detecting a visual object [15]. However, once noticed and recognized, a scent is persistent, long-lasting and will still be familiar even a long time after the experience [22]. The average human is 100 times more likely to remember a scent over something seen, heard or touched [9]. Probably scents are the most important environmental or sideway factors for marketers and that is why perfumes are applied for identity of a brand or service [12]. Even if all other senses did not existed smell is in the air we breathe. This sense generates $75 \%$ of our emotions, which has a strong impact on human memory [14]. It also plays an essential role and can become an asset in brand differentiation [8]. Further to mention, smell is 10,000 times more receptive than taste and has an overriding influence over it [10].

Despite these facts, most advertising campaigns mainly aim to use only two senses those of sight and sound and the third specially smell is largely ignored [12]. This is contradictory to the fact that we may have a $40 \%$ improvement in our mood when we're exposed to a pleasant fragrance, particularly if the fragrance taps into a joyful memory [14]. It is interesting to know, that people are born with a predisposition to learn to like or dislike various smells and depending on cultures, people do not like the same odours [8]. On an average a human being can remember more than 10,000 scents and the sensitivity of a scent experienced in the past is enough to associate with earlier memories [11]. Positive emotions, such as being happy or in love, are associated with pleasant scents, whereas negative emotions, such as feeling lonely or being sad, are associated with unpleasant scents [12]. Two potential mechanisms for the effects of odors on mood, behavior, and physiology have been proposed: pharmacological and psychological [9]. Following the pharmacological mechanism, odors exert direct effects on the central/autonomic nervous system and endocrine system independent of conscious evaluation [23]. Following the psychological hypothesis, effects depend on emotional learning, conscious perception, beliefs and expectations [15]

Scent characteristics impact highly on individual associations, learning and memories because of emotions, but scents also impact on individual cognitive behaviour when they are present in health service environments, resulting in more creativity and problem solving [12]. In service industries, if the service can use scents that can trigger memories of pleasant emotions, it could be the powerful tool in order to create loyalty to a brand or service [11]. When people have a delightful experience and later smell the same blend of scents, they immediately think of the place they connect to and want to relive the experience [9]. Some famous examples of this is the Park Hyatt Washington, D.C. hotel, which pumps a scent into the lobby using atomizers.

Krishna and Schwarz (2014) [24] describe how the use of floral fragrances can have both negative and positive effects on consumers and they suggest to sensory marketers to develop signature scents that are congenial to the products or services that they are trying to promote. There are studies showing that odours can be used as an asset to change consumer's mood, by making them feel more comfortable and relaxed [11]. There are also studies that show a positive correlation between the usage of scent and the increase of sales [9]. According to others, music is less of a complicated sensory marketing tool to manipulate than smell [25]. Of course, music is easier to control and most of the times, cheaper than purchasing the equipment to diffuse fragrances. But it seems beneficial to both purchase equipment to disperse a smell evenly and at the same time, formulate a scent that is unique to a specific brand/office.

So, there can be no doubt that emotions play an important role when people perceive, and experience different scents related to brands and service environments [12]. Ambient scenting provides a positive effect on patient perceptions of the quality of service they are receiving, the cleanliness of the office, as well as the overall personal wellness. Except the fact that it has the potential ability to create positive mood states, it can also have an influence on the time duration and perception. Spangenberg, et al. (1996) [26], found out that the presence of an enjoyable ambient smell does not affect the actual time spent in a store but does reduce the perception of the time elapsed. It drops from 11.0 minutes, when no scent is diffused to 9.6 minutes when there is one [5].

This could be very useful in a busy reception area of a dental office where patients experience anxiety and stress. Thus, dental offices are more and more recognizing the need to ensure that their patients feel comfortable which in turn helps to guarantee that they overcome their apprehensions, will feel satisfied, more likely to recommend them to friends and family and reduce the incidence of delayed or missed dental visits. On the other hand, reducing stress by odour may help dentists as well. Dentists identify treating 
nervous patients as a major source of stress for themselves [27,28], which may compromise their performance [23]. Managing dental anxiety is therefore recognized as an important issue in a modern dental practice.

Next to fear of pain, cognitive perceptions and past traumatic dental experiences, the sights (needles, air turbine drills), sounds (drilling, screaming), smells (eugenol, cut dentine), and sensations (high frequency vibrations) in the dental setting are a major cause of dental anxiety [23]. For example, the characteristic smell of eugenol, which typically clings to dental offices, may contribute to their apprehension by eliciting memories of previous unpleasant dental care experiences, involving painful restorative dentistry on vital teeth [29]. Introducing scenting in the dental office, is an excellent way to eliminate also the anxiolytic smell of harsh chemicals or detergents, which are frequently used for cleaning and disinfecting.

One way to introduce beneficial ambient odors in the dental practice, is by using essential oils that have both anti-viral and antibacterial properties [30]. Aromatherapy, can be defined as the art and science of utilizing naturally extracted aromatic essences from plants to balance, harmonize, and promote the health of body, mind, and spirit [31]. In other words, it is utilizing essential oils of aromatic plants for therapeutic purposes [32]. Unlike pharmacotherapy, there are no side effects associated with aromatherapy [31,32].

Evidence for the anxiolytic effects of inhalation of pleasant scents like essential oils is also provided by studies on both animals and man [23]. Aromatherapy should find applications in regular dental practice, such as it has indeed been observed that pleasant scents like orange and lavender appear to reduce patient anxiety levels $[23,32]$. According to the findings of a study, patients who were exposed to orange odor or lavender odor had a lower level of state anxiety, a more positive mood, and a higher level of calmness compared to the patients in the control condition [27]. In addition, the odors of jasmine tea and lavender significantly decrease heart rate and induce calm and vigorous mood states while cypress, basil, chamomile, bergamot, juniper, cedarwood, rose, ylang ylang, neroli, marjoram, geranium and clary sage aromas are also of benefit to reduce the anxiety in patients waiting for dental treatment, as they enhance the mood and calm the mind [32].

\section{Sound}

Life is full of auditory information. Every day, individuals are exposed to an incredible quantity of sounds of different quality and intensities. Sound activates the emotional part of the brain instead of the rational; it can be an efficient tool for communicating to the unconscious desires of patients and help to generate mood by creating feelings and emotions [8]. A brand that wants to impact deeply on the public must be represented by a voice that perfectly embodies the image it wants to project of itself. Music is a powerful tool for evoking emotions, because when listening to music endorphins are released, which generates sensations of pleasure
[33]. Fast and loud tempo music can trigger intense emotions but in general, low- tempo, background music has proven to be more effective in sensory branding [16].

It is evident that auditory stimuli, such as music, slogans, voices, words or familiar noises that are associated with the business, touch an individual at a deeper emotional level than visual or tactile stimuli [11]. Though, the anatomy and connectivity of the auditory system is very complex with multiple stages of processing, which involves complex interactions between inputs and existing memory and experiences as well as with other sensory systems [11]. A successful auditory sensory strategy should impact on brand's perceptions in relation to credibility and trust, positive feelings, purchasing of services and time of stay. So, the music which will play in the office should be selected very carefully based on the brand value and essence [10]. If sound is consciously applied, company has great opportunities for creating a signature sound to distinguish its brand [13].

Ancillary sounds are directly related to the object. On the other hand, ambient sounds are not directly related to a product or service but to the retail environment itself. In any case, the affective objectives consist of involving the consumer on an emotional level to generate sensations such as happiness and pleasure. The cognitive objective is to indicate the target and use the music to draw attention to this service while the behavioural objective is to change the final behaviour of the patient during the service [11].

Relaxing music can additionally change the patient's perception of the time spent in the office. Also, fast music is seen as happier than slow music, with a slow tempo naturally conveying melancholy or sadness. Classical and orchestral music not only leads customers to buy more expensive items and gives the perception of luxury services provision, but also are preferred by people with higher educational levels [12]. For example, London subway stations generally broadcast classic music on mornings to decrease stress of passengers [6].

This could be also useful in the reception area of a dental office in order to reduce patient's anxiety of the dental procedures. For example, there is one study that investigates music as a method of reducing patients' anxiety during minor surgery with local anesthesia [34]. Other studies also prove that music statistically reduces anxiety [35-37] and that it can be more beneficial than preoperative instructions alone in reducing ambulatory surgery patients' anxiety [38]. Also, classical music was proven to be as effective as Valium for some coronary care patients [39]. These and other findings have led to the "Mozart effect" which is music's lifelong effect on health, learning and behavior [39].

Additional studies approve a direct connection between the type of music played and the overall satisfaction [11]. As sound influences the customer's choice of brand it is very easy and affordable to add sound quality in the dental services. Often fundamental elements such as the soundtrack of a video are left out. The choice of an 
opening jingle, the choice of the song that accompanies brand's images and words must be made with care and paying the utmost attention to the consistency and general credibility of the message. Also, the use of English has come to suggest a social stereotype that symbolizes modernity, sophistication, progress and a cosmopolitan identity in certain cases [11].

\section{Taste}

The sense of taste is highly effective. It is the most distinct emotional sense but is hard to introduce [10]. The first image that comes up to people's mind when talking about taste is the mouth, because it is the organ which detects and identifies what we eat through the taste buds [8]. The sensorial strategy of taste is hard to introduce in all kinds of service industry because of its tangible characteristics. Although it holds a huge significance in the food and beverage industry, it can be utilized by the other sectors such as healthcare and dental services as well.

Sense of taste often interacts with the other senses and reflects the perception of flavours [11]. Smell and taste are closely linked together, and it is practically impossible to taste something without smelling it [14]. Of course, all the tastes that human perceive are related to the other senses such as vision, audition, smell and touch. But the other senses will only play a significant role in order to enhance the taste sensory area [8]. Also, colours seem to have a significant influence on the taste experience. Even though a fruit drink can be identified by its aroma, people may not recognize it, but when the colour of the drink is added, everybody can recognize the brand [12]. In this way, vision interacts with taste.

Human can distinguish between four tastes: sweet, sour, bitter and salty. A fifth taste has recently been discovered by a Japanese researcher called "umami" [8]. This last taste refers to deliciousness or savory [17]. There is no one single idea of taste that is shared by everyone [12]. For taste perceptions, the societal culture to which people belong has a strong impact on individual taste preferences [12]. An instance of sensory brand is Colgate which is among top brands for applying different tastes at toothpaste [6]. Specific taste of this toothpaste has distinguished this brand so that customers are able to find this brand even without visual or written emblem [14].

Although, as it seems, taste has a strong impact on the perception of a brand, there are a limited number of brands, which include taste in their branding strategies. According to Lindstrom and Kotler (2005) [14], nearly 16\% among total 1000 fortune companies had added tasting to their brand. Adding taste to the brand should increase the value for the patients of the dental office as well in a more aesthetic way but this remains to be investigated.

\section{Touch}

The tactile sense (or the sense of touch) is the first of human senses to develop. It is obvious why since the largest sensory organ of human senses is skin [40]. Touch is a powerful tool as well as a warning system for communicating human thoughts and emotions non-verbally [8]. Through the development of haptic sense, which means the active seeking and perception by the hand, human can capture information and get the idea of how the environment looks like. In other words, the fundamental characteristic of touch is that it can bring much sensory information simultaneously compared to other senses. For many brands, haptic perceptions are the dominant input to determining product quality [5]. According to the study of Lindstrom and Kotler (2005) [14], sense of touch falls within fifth rank and has $25 \%$ share at branding environment.

Touch stimuli such as form, material, temperature, surface, texture and weight impact on attitudes and behavior, feelings of ownership, physical/psychological interaction and willingness to pay more [12]. Brands are distinguished through sense of touching, for example, generally heavy objects have high quality [6]. Also, people by touching objects or surfaces, feel their special consistency and even without seeing them they can identify them later just by memorizing and recalling the texture [8]. Through touching people not only can identify the product, but also recognize the brand. The texture of a product influences customer's emotions hence their perception [40]. People also judge a material based on its smooth, fluffy or silky texture [40]. Krishna and Schwarz (2013), also mention how the sensation of warmth can cause people to experience intense emotions and can also affect the probability that consumers will purchase certain items [40].

It is reported that a brand is affected if customers can touch a product or for example the furniture in the dental office and receive sensory information about the quality and esthetics of the professional. Although it is difficult to achieve for healthcare industries it seems the only way to décor the dental office. Under this sense, some companies have even begun to change the tactile qualities of the materials when they replace old materials with products such as wood, linoleum, marble, and much more [40]. To further discuss the matter, in the healthcare industry, tactile marketing opportunities can be present with different ways. For example, human contact, such as a firm handshake, can do wonders to the experience and expectations of a patient in the dental office [9].

\section{Discussion}

Brands are one of the most important tools in today's global business. In the realities of today's recessed economy, and in the COVID-19 pandemic era, people are overloaded with options and conflicting information regarding just about everything. The dentist's job is to make available enough information about his services to the target market in order to be selected. Most patients gather information before choosing a dentist through brochures, internet advertisements and social media possibly despite national or regional regulations. Based on the evaluation of the gathered information, an individual chooses a dentist and along with it develops expectations which need to be fulfilled and are the driving force for the use of the healthcare system. 
In today's global business and management culture, the human senses are often proposed as useful concepts for rethinking branding in practice and theory [12]. Sensory branding is a type of marketing that appeals to all the senses (sight, smell, touch, sound, taste) in relation to the brand [11]. Of course, not all five senses have the same impact on brand's value due to the nature of different industries.

In the dental field though, all senses can have a huge and even combined impact on the brand's success. Dentistry is a health industry that is largely service oriented. In this sense, patients' satisfaction plays a pivotal role in its sustenance. The intangibility of one's services makes trials impossible and by this, it is ensuring that the experience of a patient in the destination is good. Sensory branding of dental services is mainly supported on the sense of sight and secondarily on the other senses so far. And this is because sight plays an important role both in external and internal (inside the dental office) marketing efforts. But, on the other hand, auditory, olfactory, tactile and taste stimuli can be implemented within dental office and affect patient's perception during his visit with serious results in the customer franchising policy of the office (Table 2).

Table 2: Characteristics of the five senses and their branding effectiveness in the dental office.

\begin{tabular}{|c|c|c|}
\hline Senses & Application in the dental office & Branding Results \\
\hline Vision & $\begin{array}{c}\text { Advertising (posters, leaflets), visual and verbal } \\
\text { identity, catchy logo, interior design, non-verbal } \\
\text { communication, right colors in walls, clothes }\end{array}$ & $\begin{array}{c}\text { Establishment of dentist's reputation, enhancement of the brand image, } \\
\text { perceived quality, guidance of patients' decision-making process, impact on } \\
\text { people's emotions and feelings }\end{array}$ \\
\hline Smell & Fragrant smells, enjoyable fragrances, special odors & Creation of a memorable experience, anxiolytic effects, introducing of familiarity \\
\hline Taste & Healthy beverages without sugar & Provision of high-quality service \\
\hline Sound & Relaxing music & $\begin{array}{c}\text { Reduction of patient's anxiety, creation of an emotional atmosphere, perception } \\
\text { of luxury services provision }\end{array}$ \\
\hline Touch & $\begin{array}{c}\text { Material and texture of the furniture, general decora- } \\
\text { tion, pleasant temperature }\end{array}$ & $\begin{array}{c}\text { Improvement of patient's sensory experience, competitive advantage, physical/ } \\
\text { psychological interaction }\end{array}$ \\
\hline
\end{tabular}

Visualization is used as an effective strategy before a patient makes the decision to visit the dental office in the first place. Apart from traditional visualization strategies like advertising, visual and verbal identity, design and style, marketers can also express aesthetic elements through electronic media. For example, dental offices can give a virtual tour of their onsite locations by giving a 360 o degree panoramic view on their website. Certainly, a dentist nowadays, should focus on a strong online brand, because that's where his patients expect most of his interactions to take place. Since everyone has the internet in his pocket all the time, this changes everything for all small businesses [5]. 97\% of consumers go online to find local services and $73 \%$ use online search engines to research on dental treatments [1]. Also, active social media accounts give dental clinics a face and authentic personality. These are parts of dentist's reputation in order to gain competitive advantage.

With the help of an auditory sensory strategy, brand's identity can be expressed also in the important form of sound [12]. The music which will play in the videos of the office in social media or the dental office itself, should be selected very carefully based on the brand value and essence. Relaxing music will reduce patient's anxiety and his perception of the time spent in the waiting room. Additionally, the material of the furniture, the general decoration and the pleasant temperature of the service environment will improve patient's sensory experience. Finally, fragrant smells and healthy beverages without sugar as gifts for a productive appointment will ensure high quality service provision.

In the recessed dental market of after COVID-19 era, investment in smart branding ideas which incorporate senses satisfaction in a clever way, would assure the development of the practice and its personnel. It will also recompense the professional for other expenses done in order to fulfill strict hygiene protocols for the control of the pandemic.

\section{Conclusion}

1. Sensory dental branding is the new trend in dentistry incorporating values from the five senses

2. Use of senses accelerates the quality management of the dental office.

2. Satisfaction of every sense in terms of branding could be a new tool in tomorrow's recessed dental market.

3. Sensory branding is a powerful and effective marketing technique for patient franchising.

\section{Acknowledgement}

None.

\section{Conflict of Interest}

The authors declare no conflict of interest.

\section{References}

1. Devetziadou M, Antoniadou M (2020) Branding in dentistry: A historical and modern approach to a new trend. GSC Advanced Res Rev 3(3): 5168.

2. Schivinski B, Dabrowski D (2016) The effect of social media communication on consumer perceptions of brands. J Marketing Comm 22: $189-214$.

3. Keller KL (2009) Building strong brands in a modern marketing communications environment. J Marketing Comm 15: 2-3, 139-155. 
4. Bastos W, Levy SJ (2012) A history of the concept of branding: practice and theory. J His Res Marketing 4(3): 347-368.

5. Farhadi S, Eslambolchi A, Hoseyni Hamedani E (2017) Sensory branding Impact Journals 5(8): 41-56.

6. Maymand Mahmoudi M, Ahmadinejad M, Nezami P (2012) Sensory Brand: Studying Relationship between 5 Senses and Brand Value at World's 100 Top Companies. Aust J Basic Appl Sci 6(8): 337-343.

7. Dodamgoda N, Amarasinghe K (2019) The Impact of Sensory Branding on Consumer Preference of Coffee Shops in Colombo, Sri Lanka. J Business Manag 21(6): 21-31.

8. Uddin S (2011) The Impact of Sensory branding (five senses) on consumer. A Case study on "Coca Cola". Business Administration, Master's Thesis. Karlstad Business School, Sweden.

9. Pawaskara P, Mridula G (2014) A Conceptual Model: Multisensory Marketing and Destination Branding. Symbiosis Institute of Management Studies Annual Research Conference (SIMSARC13). Procedia Econ Finance 11: 255-267.

10. Upadhyaya M (2017) Emotional Connect between Brand and Consumer through Sensory Branding. Am J Ind Business Manag 7: 352-359.

11. Rupini RV, Nandagopal R (2015) A Study on the Influence of Senses and the Effectiveness of Sensory Branding. J Psychiatry 28(2): 14-183.

12. Hultén B (2017) Branding by the five senses: A sensory branding framework. Henry Stewart Publ. 2045-855X. J Brand Strategy 6(3): 1-12

13. Baltezarević V (2020) Impact of sensory marketing on consumer behavior. Bastina 50: 183-193.

14. Lindstrom M, Kottler P (2005) Brand sense: Build powerful brands through touch, taste, smell, sight and sound. Free Press (Eds.), New York, USA.

15. Herz R (2016) The role of odor-evoked memory in psychological and physiological Health. Brain Sci 6(3):22

16. Oduguwa E (2015) "How Taste and Sight Impact Brand Loyalty in Sensory Marketing”. Undergraduate Student Research Awards.

17. Krishna A, Elder R, Caldara C (2010) Feminine to smell but masculine to touch? Multisensory congruence and its effect on the aesthetic experience. Journal of Consumer Psychology 20(4): 410-418.

18. Stillman P, Lee H, Deng X, Rao Unnava H, Fujita K (2020) Examining consumers' sensory experiences with color: A consumer neuroscience approach. Psychol Marketing 37(7): 995-1007.

19. Ou LC, Luo MR, Woodcock A, Wright AB (2004) A study of colour emotion and colour preference. Part I: Colour emotions for single colours. Color Res Application 29(3): 232-240.

20. Nan K, Epps H, Hall D (2004) Relationship between Color and Emotion: A Study of College Students. The University of Georgia. Coll Stud J 38: 3S WN: 0425203829009

21. Mikellides B (2012) Colour psychology: the emotional effects of colour perception. Colour Design. Theories and Applications 105-128.

22. Morrin M (2010) Scent marketing: An overview. In A Krishna (Edt.) Sensory marketing: Research on the sensuality of products. Routledge/ Taylor \& Francis Group 75-86.

23. Toet A, Smeets MA, van Dijk E, Dijkstra D, van den Reijen L (2010) Effects of Pleasant Ambient Fragrances on Dental Fear: Comparing Apples and Oranges. Chemosens Percept 2010 3(3-4): 182-189.
24. Krishna A, Schwarz N (2014) Sensory marketing, embodiment, and grounded cognition: A review and introduction. Jounal of Consumer Psychology 24(2): 159-168.

25. Spence C, Puccinelli N, Grewal D, Roggeveen A (2014) Store Atmospherics: A Multisensory Perspective. Psychol Marketing 31(7).

26. Spangenberg E, Crowley A, Henderson P (1996) Improving the Store Environment: Do Olfactory Cues Affect Evaluations and Behaviors? J Marketing 60(2).

27. Lehrner J, Marwinski G, Lehr S, Jöhren P, Deecke L (2005) Ambient odors of orange and Lavender reduce anxiety and improve mood in a dental office. Physiol behavior 86: 92-95.

28. Hill EJ, Jacob JI, Shannon LL, Martinengo G (2008) Exploring the relationship of workplace flexibility, gender, and life stage to family-towork conflict, and stress and burnout. Comm Work Family 11(2): 165181.

29. Robin O, Alaoui-Ismaïli O, Dittmar A, Vernet Maury E (1999) Basic Emotions Evoked by Eugenol Odor Differ According to the Dental Experience. A Neurovegetative Analysis. Chem Senses 24(3): 327-335.

30. Man A, Santacroce L, Jacob R, Mare A, Man L (2019) Antimicrobial Activity of Six Essential Oils Against a Group of Human Pathogens: A Comparative Study. Pathogens 8(1): 15 .

31. Broughan C (2005) The psychological aspects of aromatherapy. International Journal of Aromatherapy 15(1): 3-6.

32. Vagish KS (2018) Applications of Aromatherapy in managing dental anxiety. J Res Educ Ind Med 24: 17-21.

33. Kliuchko M, Heinonen Guzejev M, Monacis L (2015) The association of noise sensitivity with music listening, training, and aptitude. Noise Health 17(78): 350-357.

34. Latif IA, Salaman AN, Hanggara PS, Kadek AE, Syahrul N, et al. (2020) Effectiveness of music therapy in reducing the level of anxiety among cancer patients undergoing chemotherapy. Enfermería Clínica 30:304307.

35. Cooke M, Chaboyer W, Schluter P, Hiratos M (2005) The effect of music on preoperative anxiety in day surgery. J Adv Nurs 52(1): 47-55.

36. Thoma MV, La Marca R, Brönnimann R, Finkel L, Ehlert U, et al. (2013) The effect of music on the human stress response. PLoS One 8(8): e70156.

37. Maulina T, Djustiana N, Shahib MN (2017) The effect of music intervention on dental anxiety during dental extraction procedure. Open Dent J 11: 565-572.

38. Augustin P, Hains AA (1996) Effect of music on ambulatory surgery patients' preoperative anxiety. AORN J 63(4): 750-758.

39. Seaward BL. Managing Stress (2013) Jones \& Bartlett Publishers (Eds.), pp: 448

40. Racat M, Capelli S (2020) Touching Without Touching: The Paradox of the Digital Age. In the book: Haptic Sensation and Consumer Behaviour $33-64$ 